\title{
Study on New Body Mass Index as Criteria to Judge the Degree of College Students' Nutrition
}

\author{
Bowen Wang ${ }^{1,}$, Wemin $\mathrm{Ma}^{1}$ \\ ${ }^{1}$ School of Physical Education and Health, Hainan Tropical Ocean University, Sanya, Hainan \\ Province, China \\ âwbw1980@163.com
}

Keywords: New Body Mass Index; Skin Fold Thickness; Nutrition Degree.

\begin{abstract}
The aim of this study is to find out decision index standards of college students' nutrition degree. 593 college students between 19-22 years old (224 male and 239 female) were randomly selected and measured from several aspects, including height, weight, waist circumference and thickness of four skin folds (triceps skin fold, subscapular skin fold, abdominal skin fold, gastrocnemius skin fold). B-1/2 (H-w) calculation method is applied to calculate relevant physical indexes; Changling formula of density estimating (D) and modified Brozek formula are used to calculate body fat percentage $(\mathrm{BF} \%)$. After variance analysis, there are significant differences between mean values of total skin fold thickness of each group. The difference increases with the increasing of group limitation. According to the corresponding relationship between B-1/2(H-w) and $\mathrm{BF} \%$, it can be concluded that the new body mass index standard of college students' nutrition degree is scientific and practical.
\end{abstract}

\section{Introduction}

Nutrition degree is an important indicator to measure the fullness and nutritional status of human body. If the nutritional level exceeds the normal standard, it will affect physiological functions of the body, and has bad impacts on human health [1]. There are many index methods which can be used to determine the nutritional status and development level of human body, such as the BMI index, Quetelet index, Rohrer index, Libby index, Bailey index and Brock index [2]. But most index systems are not accurate enough to measure the nutrition enrichment degree of human body, while the other indexes cannot be applied to all circumstances [3]. For instance, the BMI index has great conflicts with BF\% method [4] in measurement, while Quetelet index can conclude that tall, thin people are fatter than short, fat people. Brock index cannot be used to people below the height of $140 \mathrm{~cm} \mathrm{[5].}$ Based on these shortcomings, a more accurate B-1/2 index (H-w) method, which is proposed by domestic scholars, is used to construct the index system for judging the nutrition degree of college students in China.

\section{Research Participants and Research Methods}

Research participants. 593 college students from 19 to 22 years old, including 224 male students and 239 female students, were randomly selected. These objects have no disability or important organ diseases.

Indexes. The following data were measured: height $(\mathrm{CM})$, weight $(\mathrm{kg})$, waist circumference $(\mathrm{CM})$, triceps skin fold thickness ( $\mathrm{mm})$, subscapular skin fold thickness ( $\mathrm{mm})$, abdominal skin fold thickness $(\mathrm{mm})$ and gastrocnemius skin fold thickness $(\mathrm{mm})$. Then, body build indexes were calculated according to data height, weight and waist circumference. The body fat percentage (BF\%) was calculated according to the formula of Changling (D) and the modified formula of Brozek:

Body build index $=$ waist $\mathrm{cm}-1 / 2$ (height $\mathrm{cm}$ - weight $\mathrm{kg}$ ), or B-1/2 (H-w)

$\mathrm{X}(\mathrm{mm})=$ triceps skin fold thickness + subscapular skin fold thickness

(male) body density $\mathrm{D}=1.0913-0.00116 \mathrm{X}$

(female) body density $\mathrm{D}=1.0897-0.00133 \mathrm{X}$ 
Body fat percentage $(\mathrm{BF} \%)=(4.570 / \mathrm{D}-4.142) * 100 \%$

Research method. measurement of height and weight. An instrument produced by Westernization Instrument Science and Technology Ltd.(Beijing) was used to measure the height and weight of students. The measurement was carried out strictly accordance with the provisions of Manual of Physical Health Survey for Chinese Students.

Measurement of waist circumference. Objects were asked to stand naturally. At the end of their exhalation, plastic measuring tape was used to measure the circumference between ribs and iliac muscles, that is, the minimum circumference of the waist $(\mathrm{cm}) .[6]$

Measurement of skin fold thickness. According to international standard, a domestic replicator of Japanese Eiken modified caliper was used to measure the skin fold thickness. Before measuring, the caliper had been strictly corrected, making its pressure stable in $10 \mathrm{~g} / \mathrm{mm} 3$. Measurement points include,

The triceps skin fold (TS): at the midpoint of upper arm acromion and olecranon, skin fold direction is parallel to the direction of long axis direction of upper arm.

The subscapular skin fold (SBS): take the subscapular skin fold direction at the lower end, lateral to 45 degrees.

The abdominal skin fold (AS), the junction of the umbilical cord and the right clavicle, the direction of the skin fold is parallel to the trunk.

The gastrocnemius skin fold (CS): take the maximum level around the inner side of shank, skin fold direction is parallel to the direction of long axis of shank.

Each position is measured 2 to 3 times, the error of the two data is controlled in $<5 \%$, then the average value is taken from data of two times. If the results are different for 3 times, the average value of the two similar value is taken[7].

Statistical processing. B-1/2 (H-w) value of each object is calculated by using grouping method. According to the five set of class intervals, male students were divided into five groups. According to the seven set of class intervals, female students were divided into seven groups.

The values of $\mathrm{TS}+\mathrm{SBS}, \mathrm{AS}+\mathrm{CS}$, TS $+\mathrm{SBS}+\mathrm{AS}+\mathrm{CS}$, body weight and body fat percentage were calculated and analyzed by means of variance analysis ( $\mathrm{F}$ test), then the results were compared with each other.

Excel2003 software and SPSS17.0 software were used to process and analyze data.

\section{Research Results}

Corresponding relationship between B-1 / 2 (H-w) index group and the status of skin fold thickness. After grouping through B-1 / 2 (H-w) indexes, there were 13 male students in the group of 9.9 and below, 40 students in group between 10-14.9, 75 students in group between 15-19.9, 59 students in group between 20-24.9, and 37 students in group of 25 and above. There were 35 female students in the group of 6.9 and below, 52 students in group between 7-13.9, 84 students in group between 14-20.9, 43 students in group between 21-27.9, and 25 students in group of 28 and above. The relationship between B-1 / 2 (H-w) index group and the status of skin fold thickness can be seen in table 1 and table 2.

Table 1. Skin fold thickness of each group of male students between 19-22 years old

\begin{tabular}{lllll}
\hline group & Group limits & TS+SBS & AS+CS & $\begin{array}{l}\text { TS+SBS+AS+ } \\
\text { CS }\end{array}$ \\
One & $\sim 9.9$ & $12.51 \pm 1.22$ & $17.39 \pm 4.36$ & $29.90 \pm 4.87$ \\
Two & $10 \sim 14.9$ & $17.32 \pm 1.83$ & $22.26 \pm 4.11$ & $39.58 \pm 4.92$ \\
Three & $15 \sim 19.9$ & $26.95 \pm 2.68$ & $31.74 \pm 3.86$ & $58.69 \pm 5.23$ \\
Four & $20 \sim 24.9$ & $36.25 \pm 2.42$ & $43.66 \pm 5.28$ & $79.91 \pm 6.87$ \\
Five & $25 \sim$ & $42.62 \pm 3.13$ & $48.36 \pm 5.26$ & $90.98 \pm 8.05$ \\
\hline
\end{tabular}

note: triceps (TS) subscapular (SBS) abdominal (AS) gastrocnemius (CS) 
Table 2. Skin fold thickness of each group of female students between 19-22 years old

\begin{tabular}{|c|c|c|c|c|}
\hline group & $\begin{array}{l}\text { Group } \\
\text { limits }\end{array}$ & $\mathrm{TS}+\mathrm{SBS}$ & $\mathrm{AS}+\mathrm{CS}$ & $\begin{array}{l}\mathrm{TS}+\mathrm{SBS}+\mathrm{AS}+\mathrm{C} \\
\mathrm{S}\end{array}$ \\
\hline one & $\sim 6.9$ & $18.55 \pm 2.56$ & $26.68 \pm 3.28$ & $45.23 \pm 7.55$ \\
\hline two & $7 \sim 13.9$ & $24.27 \pm 4.21$ & $33.55 \pm 5.62$ & $57.82 \pm 4.36$ \\
\hline three & $14 \sim 20.9$ & $34.54 \pm 6.74$ & $45.19 \pm 6.89$ & $79.73 \pm 9.52$ \\
\hline four & $21 \sim 27.9$ & $43.82 \pm 5.43$ & $55.37 \pm 8.46$ & $99.19 \pm 8.26$ \\
\hline five & $28 \sim$ & $48.63 \pm 8.24$ & $61.24 \pm 11.43$ & $109.87 \pm 12.07$ \\
\hline
\end{tabular}

From above statistical results, it can be seen that no matter male or female students, the values of triceps skin fold thickness, subscapular skin fold thickness, abdominal skin fold thickness and gastrocnemius skin fold thickness were increasing with the increasing B-1/2 (H-w) indexes of each group. Thus, B-1/2 (H-w) index can be used to identify human nutrition structure through quantitative evaluation.

Significance test of differences between mean values of total skin fold thickness of students in each group. Total Skin fold thickness refers to the total value of thickness of triceps skin fold (TS), subscapular skin fold (SBS), abdominal skin fold (AS) and gastrocnemius skin fold (CS). Since multiple means were involved in the difference test, variance analysis method was used. After obtaining results with significant differences, multiple comparisons should be made to determine the significant differences between each group. The results are shown in table 3 and table 4.

Table 3. Variance analysis of total skin fold thickness of male students in each B-1 / 2 (H-w) index group

\begin{tabular}{llllll}
\hline & $\begin{array}{l}\text { Sum of } \\
\text { Squares }\end{array}$ & df & Mean Square & F & Sig. \\
\hline Between & 82889.512 & 4 & 20722.378 & 545.255 & .000 \\
Groups & 8323.077 & 219 & 38.005 & & \\
Residual & 91212.589 & 223 & & & \\
\cline { 1 - 5 } Total & & & & & \\
\hline
\end{tabular}

Table 4. Variance analysis of total skin fold thickness of female students in each B-1 / 2 (H-w) index group

\begin{tabular}{llllll}
\hline & $\begin{array}{l}\text { Sum of } \\
\text { Squares }\end{array}$ & df & Mean Square & F & Sig. \\
\hline Between & 22609.153 & 4 & 5652.288 & 170.330 & .000 \\
$\begin{array}{l}\text { Groups } \\
\text { Residual }\end{array}$ & 7765.151 & 234 & 33.184 & & \\
Total & 30374.304 & 238 & & & \\
\hline
\end{tabular}

According to the results of statistical analysis, there were significant differences between male and female students from different $\mathrm{B}-1 / 2(\mathrm{H}-\mathrm{w})$ index $\operatorname{groups}(\mathrm{P}<0.001)$. After multiple comparisons, the results showed that the differences between each groups were significant. Thus, B-1/2 (H-w) index grouping can be used to distinguish different levels of subcutaneous fat, and has certain practical values in quantitative determination of nutritional enrichment of human body.

The determination of nutrition degree through new body indexes. Referring to the domestic and foreign documents, it can be found that skin fold thickness is an effective way to determine nutrition enrichment of human body [8]. According to the rate of body fat, $(\mathrm{BF} \%$ was calculated through modified Brozek formula $\mathrm{BF} \%=(4.570 / \mathrm{D}-4.142) * 100 \%$ [9]; D value was calculated through Changling formula: male $\mathrm{D}=1.0913-0.00116 \mathrm{X}$ and female $\mathrm{D}=1.0897-0.00133 \mathrm{X}$ [10]) an 
evaluation table of five grades were established to evaluate the nutrition levels of college students. Detailed results are shown in table 5

Table 5. Evaluation indexes on nutrition levels of college students aged from 19 to 22

\begin{tabular}{|c|c|c|c|c|c|c|}
\hline & & $\begin{array}{l}\text { Male } \\
\text { students }\end{array}$ & & & $\begin{array}{l}\text { Female } \\
\text { students }\end{array}$ & \\
\hline \multirow[t]{2}{*}{ thin } & $\begin{array}{l}\text { B-1/2 } \\
(\mathrm{H}-\mathrm{w})\end{array}$ & $\mathrm{TS}+\mathrm{SBS}$ & $\mathrm{BF} \%$ & $\begin{array}{l}\text { B-1/2 } \\
(\mathrm{H}-\mathrm{w})\end{array}$ & $\begin{array}{l}\text { TS+ } \\
\text { SBS }\end{array}$ & $\mathrm{BF} \%$ \\
\hline & $\sim 9.9$ & $\sim 12.5$ & $\sim 10$ & $\sim 6.9$ & $\sim 18.5$ & $\sim 15$ \\
\hline good & $10 \sim 14.9$ & $\begin{array}{l}12.6 \sim \\
22.5\end{array}$ & $\begin{array}{l}10.1 \sim \\
15\end{array}$ & $7 \sim 13.9$ & $\begin{array}{l}18.6 \sim \\
28.5\end{array}$ & $\begin{array}{l}15.1 \sim \\
20\end{array}$ \\
\hline ordinary & $15 \sim 19.9$ & $\begin{array}{l}22.6 \sim \\
32.5\end{array}$ & $\begin{array}{l}15.1 \sim \\
20\end{array}$ & $14 \sim 20.9$ & $\begin{array}{l}28.6 \sim \\
38.5\end{array}$ & $\begin{array}{l}20.1 \sim \\
25\end{array}$ \\
\hline Slightly fat & $20 \sim 24.9$ & $\begin{array}{l}32.6 \sim \\
42.5\end{array}$ & $\begin{array}{l}20.1 \sim \\
25\end{array}$ & $21 \sim 27.9$ & $\begin{array}{l}38.6 \sim \\
48.5\end{array}$ & $\begin{array}{l}25.1 \sim \\
30\end{array}$ \\
\hline obese & $25 \sim$ & $42.6 \sim$ & $25.1 \sim$ & $28 \sim$ & $48.6 \sim$ & $30.1 \sim$ \\
\hline
\end{tabular}

Note: mean value \pm standard deviation, triceps (TS) subscapular (SBS), BF \%stands for body fat rate

In table 5, indexes of $\mathrm{B}-1 / 2(\mathrm{H}-\mathrm{w})$ corresponds to $\mathrm{BF} \%$, and establish the evaluation standards of college students nutrition (five grades). This kind of index evaluation method is simple and convenient in practical application; its requirements on measurement conditions and tools are not high, and is very economical and practical. Through indexes of B-1/2 (H-w), the degree of nutrition can be calculated. Hence, it is an effective tool to determine human subcutaneous fat content and nutrient enrichment degree.

\section{Discussions}

The new body index B-1/2 (H-w) was used to divide male and female students (224 male students and 239 female students) into different groups. The class interval between male students was 5, while female students was 7. There were ten groups totally. In each group, values of thickness on students' triceps skin fold, subscapular skin fold, abdominal skin fold and gastrocnemius skin fold were quantitatively analyzed. The results showed that, no matter male or female students, the values of thickness were increasing with the increasing B-1/2 (H-w) indexes of each group.

Single factor analysis of variance was used to test the significance of means on skin fold thickness of 5 male and 5 female groups. The results showed that the difference was significant $(\mathrm{P}<0.001)$. After multiple comparisons, the differences of male and female students in each index group were also statistically significant $(\mathrm{P}<0.01)$, which fully proved that the new physical index method had good practical values in the quantitative analysis of human nutrition degree.

Referring to domestic and foreign established standards of body nutrition, values on body fat percentage $(\mathrm{BF} \%)$ were used to establish evaluation table on nutrition levels of college students. This kind of index evaluation method is simple, convenient, economical and practical; its requirements on measurement conditions and tools are not high. Hence, it is an effective tool to determine human subcutaneous fat content and nutrient enrichment degree.

\section{Acknowledgement}

Fund Project: This paper is supported by Natural Science Foundation of Hainan Province (Project No. 809014).

\section{References}

[1] D.Y. Zhang, H. Huang, A study on obese evaluation in terms of body fat rate based on medical indexes, J. J Journal of Xi'an Institute of Physical Education. 24 (2007) 67-70. 
[2] S.W. Qiu, Progresses in the evaluation of children's growing development and nutritional status in China, J. Chinese Journal of School health.35 (2014) 158-160.

[3] D.M. Meng, W.M. Ma, et al., A new method on body mass index (BMI) evaluation of adolescent students, J. Modern Preventive Medicine. 39 (2012) 1092-1094.

[4] M.X. Zheng, L.B. Zheng, et al., A preliminary study on the evaluation of obesity standards of Chinese and Han population with skin fold thickness and body fat rate, J. Journal of Tianjin Normal University (Natural Science Edition). 33 (2013) 68-72.

[5] W.M. Ma, A new index method for evaluating students' nutrition level. J. Chinese Journal of School Health. 32 (2011) 1096-1097.

[6] National research group on students' physical health, Manual of Physical Health Survey for Chinese Students. 2010:63-65.

[7] J.P. Bao, L.B. Zheng, et al., Age variation of skin fold thickness of Han people lived in Qionghai, Hainan Province, J. Acta Anthropologica Sinica .32 (2013) 1-8.

[8] X.J. Wu, H. He, et al., Comparative study on the method of estimating young adults' body fat percentage by skin fold thickness J. Journal of Beijing Sport University. 32 (2013) 46-49.

[9] J. Brozek, F. Grande, J.T. Anderson, Keys A. Densitometric analysis of body composition, revision of some quantitative assumptions, J. Ann NY Acad Sci. 17(1963)110-113.

[10] Y. Pan, C.G. Hou, Evaluation of the effect of joint intervention on improving the physical health of adolescents, J. Chinese Journal of School Health.35 (2014) 1211-1213. 